\title{
Viewing Mathematics Teachers' Professional Identity in the Kingdom of Saudi Arabia through the Lens of Social Theory of Learning and Gender Schema Theory
}

\author{
AlghamdiHamad Abdullah $\mathbf{J}^{1}$, Mohd Ali Samsudin², ShamimahParveen Abdul Rahim ${ }^{3}$, Mohammed \\ Ali HAlqarni ${ }^{4}$, Mohd Erfy Ismail ${ }^{5}$ \\ ${ }^{1,4}$ Saudi Ministry of Education, Saudi Arabia \\ ${ }^{2,3}$ School of Educational Studies, Universiti Sains Malaysia, \\ ${ }^{5}$ Faculty of Technical and Vocational Education, Universiti Tun Hussein Onn Malaysia, Malaysia
}

\begin{abstract}
The purpose of the study is to explore the profile of the professional identity of Mathematics teachers in the Kingdom of Saudi Arabia under the influence of Social Theory of Learning and Gender Schema Theory. The descriptive approach is used in this study. The sample size of this study is 600 secondary Mathematics teachers. This study used an adapted version of the questionnaire designed by Albaqi'i (2014) to profile the Mathematics Teachers' Professional Identity (TPI) of the participants. The findings of the study showed that there is no significant difference of Mathematics TPI in gender wise, but there is significant differences of Mathematics TPI based on teaching experiences and qualifications among the Mathematics teachers in Kingdom of Saudi Arabia.The finding of the profile analysis gives some implications to understand how TPI is evolved among Mathematics teachers in the Kingdom of Saudi Arabia through the influences of teaching experience and professional development, which represent by their qualifications. The findings also informed that male and female Mathematics teachers did not perceive their professional identity differently, which suggest that Saudi Arabia culture permit equal participation in building their professional identity.
\end{abstract}

\section{Keywords}

Mathematics, Teachers' Professional Identity, Social Theory of Learning, Gender Schema Theory

Article Received: 20 September 2020, Revised: 30 November 2020, Accepted: 18 December 2020

\section{Introduction}

In the last decade, a series of studies have investigated the impact of culture on different societies, focusing mainly on Western counterpart. However, little attention has been given to the Arab World in order to understand the influence of culture in the Arab society (El Sherif, 2012). Islam is influential upon Muslims' lifestyle and ways of thinking. Abu-Raiya and Pargament (2011) stated that empirical Islamic psychology underscores the relevance of Islam to Muslims' lives and well-being, and the need for greater attention to the Islamic religion when dealing with Muslim populations. Failure to do so could lead to an incomplete and perhaps distorted picture of Muslims.

Ali, Taqi, and Krishnan (2010) claimed that in a collective culture decision styles that maintain and reinforce consensus, such as consultative style, is valued and emphasised. On the other hand, research shows that, decision styles that are serving an individual's interest are embraced in individualistic cultures as reported in Ali, Taqi, and Krishnan (2010). Furthermore, Arabs in general tend to be more collectivist due to Islamic teaching and Arab traditions that has group loyalty, respect for family members, and remaining humble while interacting with others as a paramount (Ali, Taqi, \& Krishnan, 2010). Arabs were found to emphasise consultation and they demand humility when dealing with others (Ali, Taqi, \& Krishnan, 2010). Scholars have previously mentioned that due to different values, customs, language, and religion non-Arab find socializing really difficult (Atiyyah, 1996). Ali, Taqi, and Krishnan (2010) argue that if Arabs were to be treated with arrogance in any context, it could damage the relationships immensely if not end it completely. A previous research has found that foreign workers in Arab country struggle with subjective problems, such as personal relationships being more important than professional relationships (Ali \& Azim, 1996). While the study of identities helps increase understanding of how Arab peoples define themselves, the study of cultural values allows for a deeper understanding of the goals that motivate them. The study of values has been essential to the understanding of cultural differences and similarities. Values are beliefs or concepts that pertain to desirable behaviours or end states; they transcend specific situations and guide the selection of events and behaviour (Schwartz, 1994). The central role values play in everyday life and the different profiles that emerge across different ecosystems has placed values at the core of cross-cultural research (Smith, Fischer, Vignoles, \& Bond, 2013).

Researching on the formation of TPI is very important in understanding how teachers feel towards their changing roles in today's schools. This is because many educational issues are changing rapidly, forcing teacher to deal and control differently with these changes and how to face them as reported in Beijaard, Meijer, and Verloop (2004). The development of the TPI has received more attention from decision makers and researchers and based on the fact that reform of the education system set new requirements and standards for quality related to the TPI. This means increasing the teacher's awareness of teaching profession in terms of, (i) how the teacher will work? (ii) how the performance could be improved and (iii) how the 
professional growth occurs? as highlighted inŽivković (2013).

TPI is defined as the sense of the teacher in his or her own role through the roles that they performs inside and outside the school, and through the knowledge, skills and learning competencies, and the commitment to the values and ethics of his profession (Albaqi'i, 2014). While others defined professional identity as the group of attitudes, beliefs and hobbies that individual has in matters and attitudes related to the profession that the individual seeks to achieve (Alzubaidi \& Al-Kahali, 2014). According to Goldin, Hannula, Heyd, Jansen, Kaasila, Lutovac and Pantziara (2016) reported that professional identity is the way in which the individual is associated with a specific society and participate within it, and it is a dynamic structure changes over time. In general, the TPI is best described as the teacher's own vision as an expert in the academic content of the subject, an expert in teaching, and an educational expert. A number of factors influence the forming of the TPI, including the context and environment of the teaching, the teaching experience, and the curriculum vitae. The TPI is a continuous process of integration between subjective and professional aspects.

\section{Mathematics Teachers' Professional Identity}

In the context of Mathematics education and learning, Goldin et al. (2016) reviewed a number of studies and research focused on identity and Mathematics, and noticed there is increased in interest in the subject of identity, reflecting the interest in social, cultural and political aspects in the teaching and learning of Mathematics. It also noticed that these studies were divided into two directions; (i) to examined the identity of the student, and (ii) second focused on the identity of the teacher. Moreover, Goldin et al. (2016) reported that most of the studies that investigated identity, whether for students or teachers, linked between identity and attitudes, beliefs, self-efficacy and motivation towards Mathematics education and learning (Goldin et al., 2016).

According to Graven and Lerman (2014), most of the literature in Mathematics education consider the identity of the Mathematics teacher as the ways in which the individual becomes a teacher of Mathematics and belongs to the profession of education including paths of professional growth in narrative and discursive terms. Research literature indicates that the identity of the teacher is an alternative means of determining teacher learning and not necessarily a global perspective. Research is still needed to gain a broad understanding of the concept of teacher's identity. At the same time, research literature showed that the concept of identity exists intensively in social sciences, and researchers in Mathematics teaching need to determine how the term is used, identify sources and references of their views, and the relevance and relevance of teaching and learning Mathematics as reported in Graven and Lerman (2014).

Many factors contribute in forming the TPI as reported in previous research, such as Bolívar and Domingo (2006) and Graven and Lerman (2014), and the major development in the teacher work and the educational challenges that affect the teacher's performance as stated in Coldron and Smith (1999). Due to that, it was necessary to measure the TPI, especially since this topic has not been widely addressed in the Arab environment. Few previous researches only tried to highlight the important aspect of the TPI in the educational process as reported in Hussein (2017), Abdulghani and Abulnaeem (2016) and Albaqi'i (2014). Thus, this field is highly needed to be addressed in the Arab environment due to the complex environment and culture in this area.

Furthermore, few researchers like Graven and Lerman (2014) and Graven (2004) argued that there are many aspects of the TPI that are integrally connected to the particular nature of the subject Mathematics. TPI differs only with regard to beliefs about and views of the subject itself, which plays a significant role among Mathematics TPI. However, many researchers have argued that researchers working with the notion of Mathematics teacher's identity have not clearly defined and operationalized the notion as reported in Graven and Lerman (2014). Moreover, despite the importance that has been highlights in the literature for studying the Mathematics TPI, only few and inadequate body of research has been performed in the Arab environment.

This view is supported by the argument that the contribution of Mathematics to scientific and technological development has influenced Mathematics itself, and has become a tool for developing thinking and achieving relationships in an integrated framework in the individual after viewing it as merely acquiring normal mathematical skills. Traditional Mathematics teaching methods is no longer acceptable today. Ball (2003) had reported that teaching subject like Mathematics requires the necessary skills that must be exercised by the teacher who is able to work effectively, whether it is related to the objectives of teaching Mathematics, or how to prepare, implement and evaluate. The complexity of Mathematics teachers to develop the necessary skills can be varied depending on their interpretations of their ongoing interaction with their context (Beijaard et al., 2004). Kelchtermans (2009) stated that teachers develop an interpretative framework during their careers and that this framework is formed and restructured through interaction between individual teachers and social, cultural and structural working conditions in the context of their work. The measurement of this interpretive framework is called professional which relates to how teachers perceive themselves as teachers, based on their interpretations of their ongoing interaction with their context (Beijaard et al., 2004).

Measuring and developing the TPI has a significant impact on the process of education as reported inAmbusaidi, Alhashmi, and Al-Rawahi (2014). Teacher identity has been viewed as a conceptual tool that is critical to understanding teacher education (King, 2015). However, it has been mentioned earlier that most of the previous research that has been conducted on TPI and its measurements has been conducted in Western countries contexts while limited research seems to have been conducted in the Arab countries in general and Saudi Arabia in particular (Abdulghani \& 
Abulnaeem, 2016). This means that the understanding of the construct of TPI and its measurements are significantly shaped by the findings and revelations of Western theories and their studies. This is not to say that such findings are of no use to education field in the Kingdom of Saudi Arabia. However, these findings and revelations may not provide a deep understanding of the construct of TPI and the way it should be measured and developed in the Saudi context considering the consensus among researchers and practitioners on the idea that cultural differences between individuals from different countries influence their behavior and ways of thinking (Hofstede, 2003). Thus, and due to the lack of research on TPI and its measurements in the Kingdom of Saudi Arabia context, it is expected that the findings of this study would be of a great use to the body of research on TPI and its measurements as such findings could provide a cross-cultural understanding of how TPI is understood and developed across cultures and countries in the Middle East educational context in general and the in the context of the Kingdom of Arab Saudi education in particular.

Furthermore, the findings of this study are expected to be significant to the educational authorities in the Kingdom of Saudi Arabia in designing and conducting a professional development programs that helps teachers to develop their professional identity in general and Mathematics TPI in particular as stated in Sabanciogullari and Dogan (2015). Such programs are significant in developing the entire educational activities in educational field in Saudi Arabia. Moreover, Saudi Arabia had significant transformed in the educational process. Several conferences were held to support the development of the teachers and the education in the Kingdom of Saudi Arabia and the first conference was in held in the year of 1973, the second conference was in the year of 1995 and the third one in the year of 1999.Hence, this study aims to profile Mathematics TPI based on gender, teaching experience and qualification in the Kingdom of Saudi Arabia.

\section{The Psycho-Sociological Perspective of Teachers' Professional Identity}

One of the two main underlying theories for this research is based on the concept of a community of practice as a Social Theory of Learning which has been highlighted by Farnsworth, Kleanthous and Wenger (2016). The concept of community of practices is based on the notion that learning does not rest with the individual, but is a social process that is situated in a cultural and historical context. Thus, the concept of TPI and community are closely linked. This can be explained by looking at the on how teachers negotiate their identity as participants in a community of practice, as an example, a community of teachers in schools or in wider context. This bring to another identity about how teachers express their competence in their own professional community which make them have been recognized as the members of that particular community.

One of the characteristics of social theory of learning is its emphasis on the locally social, that is on how learning, knowing, and identity are inherently linked to practices as they unfold in a particular situation. Identity is seen as a dynamic and ever-evolving construct that is constantly negotiated as people engage with one another. Also linking identity and learning, Wenger (1998) wrote that his work on communities of practice starts with the assumption that "engagement in social practice is the fundamental process by which we learn and so become who we are". Further, he wrote identity is a "layering of events of participation and reification" connected to a practice. Still according to Wenger (1998), participation and reification are also the two constituent elements of meaning as it evolves when one engages with others in a practice. Identity, in the context of this study, may be viewed as the meaning of 'who Mathematics teacher are' that emerges in a Kingdom of Saudi Arabia context.

In relation with this study, the aim using social theory of learning is to ensure that indicators in the Mathematics TPI instrument can be used to measure the Mathematics TPI in the context of the Kingdom of Saudi Arabia. From research on Mathematics teacher education, there is known a great deal about some of the specialty of Mathematics teachers' knowledge (Ball, Lubienski, \& Mewborn, 2001) and their beliefs (Philipp, 2007). However, there is a need to understand better the dynamics of Mathematics teachers' learning, as they move across different cultures and unite their experiences into a role as a professional teacher $(\mathrm{R} \emptyset$, 2015) which make the TPI should be studied among Mathematics teachers in the Kingdom of Saudi Arabia context.

Lave and Wenger's social theory of learning is used to underpin this study in order to show how the teachers develop a mathematical learning community. Lave and Wenger assert that all learning has a social origin for there is no activity that is not situated as stated in Lave and Wenger (1991) and learning is a process whereby agent, activity and the world mutually constitute each other (Lave \& Wenger, 1991). The starting point for learning is not the individual but the social practice in which the community is engaged. So, Lave and Wenger describe learning as situated in communities of practice and describes how 'newcomers' to the community become more knowledgeable in the practice through a process of 'legitimate peripheral participation', a bridge between the individual and the community of practice. Through such participation a Mathematics teacher learns to become a full member of the community, to reach full participation and become a more knowledgeable and skilful Mathematics teacher.

Adler (1998), in her consideration of this theory for the Mathematics classroom, notes that full participation is not an endpoint in learning or knowing all there is to know about the practice, but involves mastery having control over the resources (physical and mental) present in the practice. Learning within the community of Mathematics teachers requires these resources to be accessible to a Mathematics teacher, and Lave and Wenger (1991) describe two ways in which this mastery can develop. First, it is developed as a result of transparency whereby the Mathematics teachers is 
able to see not only what to do but why, and with this knowledge mastery, rather than imitation is achieved. Such transparency, or the lack of it can "enable, obstruct or even deny peripheral participation and hence access to the practice" (Adler, 1998). Secondly, legitimate participation involves "learning how to talk (and be silent) in the manner of full participants" (Adler, 1998). Lave and Wenger (1991) assert that "the purpose is not to learn from talk as a substitute for legitimate peripheral participation; it is to learn to talk as a key to legitimate peripheral participation".

Adler observes that social theory of learning faces its greatest challenge when teachers try to apply it to the practice of teaching and learning in schools (Adler, 1998); if there is an attempt to describe the Mathematics classroom as a community of practice, what is the nature of the practice - teaching, learning, Mathematics? Who are the oldtimers - teachers or older pupils - and what are the newcomers learning to become? It is quite difficult to claim that they are learning to become teachers since this will apply to few of them. Few, also will become mathematicians, even if teachers see themselves as mathematicians, yet Mathematics is what they are doing. In addition, what is the product of the community of school Mathematics learners? Adler (1998) sums these questions up in asking, "what might constitute legitimate peripheral participation in the Mathematics classroom". In this sense, it is difficult to see how the Mathematics classroom can be equated to the work, or even the social, contexts of adults. The children are not there by choice (Ernest, 1998) if they share the aims of the teachers these are seldom made explicit. The newcomer or the old-timer, peripheral and full participation models appear to break down.

Adler (1998), however, goes on to argue, "Lave and Wenger have, nevertheless, constructed concepts that could provoke insights into learning and teaching Mathematics in school". In particular, she notes the relevance of transparency to the use of resources (physical and mental) for learning Mathematics in the classroom, where the child may find the resource opaque and so focus on the resource rather than on the underlying Mathematics. This opacity of resource can lead to alienation from the practice. Furthermore, Adler relates talking within and about Mathematics to the difference between children using language to help solve a problem and that used to explain it to others. In an attempt to explain the sense in which the classroom is a community of practice, she draws on idea of discourse, "language as it is used to carry out the social and intellectual life of a community" (Mercer, 1995). Adler (1998) argues that the discourse of the classroom is not that of the mathematician, nor the apprentice, nor the everyday, but that it is a distinctive discourse "a social practice with specific timespace relations, activities and discursive practices. School Mathematics is a distinct practice. A hybrid where there are recontextualizations from the discipline of Mathematics and its applications into the curriculum".

A model of social learning takes into account the concept of identity and connects it to the concept of practice. The shift is occurred in terms of the perspective on Mathematics teachers' learning from a psychological-individual transformation to a more holistic socio-cultural process in terms of identity development in the context of Kingdom of Saudi Arabia. It is theorized that that identity is a "self-incommunity", referring to processes of participation and perception within communities of practice. Identity is always connected to activity or practice and therefore identity is a useful construct for understanding the formation of mathematical teaching (Grootenboer,Lowrie, \& Smith, 2006) Therefore, it is possible to consider the relationships between Mathematics teachers' identities and their participation in social practices (Skott, 2013) which naturally comprise both teaching in classrooms and teachers' learning in professional development courses.

In summary, Mathematics TPI is not as predetermined or given but rather as constructed within an active process of creation and recreation that is reflected in Britzman (2003) description of learning to teach as the process of becoming: a time of formation and transformation, of scrutiny into what one is doing, and who one can become. This is supported by study done by Skott (2019) which emphasize that TPI is defined as a shifting experience of being a teacher, becoming a teacher, and sense of belonging as a teacher. Therefore, TPI provides a framework for Mathematics teachers to construct their own ideas of 'how to be', 'how to act' and 'how to understand' their work and their place in the Kingdom of Saudi Arabia context. Importantly, Mathematics teacher identity is not something that is fixed nor is it imposed; rather it is negotiated through experience and the sense that is made of that experience (Sachs, 2005).

\section{Gender Identity and Teachers' Professional Identity}

As social theory of learning recognizes the importance of imitation and modelling in the development of social behaviours, it can be applied to gender development, modelling, or observational learning, refers to a person's tendency to learn vicariously by observing other people engage in gender-typed behaviours and witnessing the responses (rewards or punishments) that these people receive from others. Through this process, human learn what behaviours are characteristic of each gender and the consequences likely to be associated with engaging in samegender and other-gender behaviours. This led to another theory which support the study of TPI in Saudi Arabia context which is gender schema theory. In this study, it is theorized that gender will influence the construction of Mathematics TPI in Saudi Arabia context.

This study also uses Gender Schema Theory. Smelser and Baltes (2001) stated that Gender Schema Theory is a cognitively based theory that uses an information processing approach to explain how gender development occurs. The basis of this model is the cognitive representation called a schema. A schema is an organizing structure that helps simplify and categorize new information.

Gender schema theory proposes that the phenomenon of sex typing derives, in part, from gender-based schematic 
processing, from a generalized readiness to process information on the basis of the sex-linked associations that constitute the gender schema (Bem, 1981). In particular, the theory proposes that sex typing results from the fact that the self-concept itself gets assimilated to the gender schema. The distinction between male and female serves as a basic organizing principle for every human culture. Although societies differ in the specific tasks, they assign to the two sexes, all societies allocate adult roles on the basis of sex and anticipate this allocation in the socialization of their children. Not only are males and females expected to acquire sex-specific skills, they are also expected to have or to acquire sex-specific self-concepts and personality attributes, to be masculine or feminine as defined by that particular culture (Barry, Bacon, \& Child, 1957). The process by which a society thus transmutes male and female into masculine and feminine is known as the process of sex typing. It is important to note that gender schema theory is a theory of process, not content. Because sex-typed individuals are seen as processing information in terms of and conforming to whatever definitions of masculinity and femininity the culture happens to provide, it is the process of partitioning the world into two equivalence classes on the basis of the gender schema, not the contents of the equivalence classes, that is central to the theory. Social approaches to gender development view gender differences as due to the differential treatment male and female $\mathrm{s}$ receive from the people in their lives and the pervasive gender stereotyped messages that people are exposed to in their environment. This approach emphasizes socialization in the family, society, and wider culture.

Today it becomes self-evident that gender identities and gender relations are significantly connected with the cultural progress since they determine the daily life of each person, family, workplace, and wider community. Schalkwyk (2000) reported that global changes, especially social and economic turbulences push the cultural values toward modification and variations, different interests intervening this process. Traditional gender norms of masculinity, prioritizing domination, competitiveness and short-term success on the individual or corporate scale or the so-called hegemonic masculinity (Connell \&Messerschmidt, 2005). The norms of femininity contradict with empowerment and participation of women in social activities. Gender identity refers to the degree to which a person perceives the self to be masculine or feminine, considering the meaning of masculine or feminine in a given culture (Perry \&Pauletti, 2011). Societal norms of ideal masculine and feminine person may inform our gender identity, when we compare our features with those from a gender category. Gender identity can justify the specific gendered behaviour in the social sphere (Tobin, Menon, Menon, Spatta, Hodges, \& Perry, 2010). Therefore, gender identity influences how people perceive the world around them and how they behave.

First introduced by Sandra Bem in the year of 1981 as an expansion of gender schema theory further explores how gender and sex-role expectations are culturally conveyed in society. Gender schema theories emphasize that early on, children begin to learn and understand gender labels or stereotypical terms used to describe characteristics of girls and boys (Martin and Halverson, 1981). Bem (1983) described an individual's ability to encode and to organize information including information about the self, in terms of cultural definition of maleness and femaleness that constitutes the society's gender schema.Similar to social learning theory, Bem postulates that children learn gender roles by being rewarded for some behaviours and punished for others, as well as by modelling behaviour seen by others. Bem believed that although children learn gender norms through observation, they are not passive in this process but rather actively seek examples and models of behaviours and mannerisms. Martin and Halverson added that gender identity formation and subsequent self-socialization, or the process by which we actively influence our own development and outcome, begin as early as two to three years of age. By using for gender, children develop schemas, or conceptual frameworks, that propel them to perform activities society deems typical of their gender (Bussey, 2011). Gender schemas allow for children to have culturally specific expectations of behaviour based on their gender. With behaviours conforming to stereotypes for their own gender, children are able to gain cognitive consistency and process new information through their schemas and retain and even distort memories to fit within their understanding of gender (Bem, 1981; Martin \& Halverson, 1981). This study tries to test whether Gender Schema Theory somehow can be a basis for the formation of Mathematics TPI in the context of the Kingdom of Saudi Arabia.This study speculated that that the construction of TPI influence by social surrounding. However, as this study conducted in Saudi Arabia context where the cultural factor also possibly plays a role in enabling teachers to perceived themselves to classify themselves based on gender identity. The conceptual framework has successfully built the case which explained how gender schema theory is congruent with the principle of social learning theory. The attempt to link between social learning theory with gender schema theory justify this study to research the influence of gender on the construction of Mathematics TPI in Saudi Arabia context.

\section{Methodology of the Study}

This study used adapted version of the questionnaire that designed by Albaqi'i (2014) The adapted instrument contains 45 items. Prior to conducting the main study, a small-scale pilot study was undertaken. The importance of pilot studies for checking the appropriateness of data collection procedures and instruments and enhancing the quality of research has been widely stressed in the literature (Creswell, 2003; Dörnyei \& Taguchi, 2009;Gliner, Morgan, \& Leech, 2011;Loewen \& Plonsky, 2015; McBurney \& White, 2009; Riazi, 2016). Such researchers maintain that pilot study can provide valuable feedback on the clarity of the language used in the instrument by pointing out any ambiguity in item wording or difficulty of instructions, the validity and reliability of the instrument, and the amount of time needed to complete the instrument.The pilot study undertaken in this study was carried out by using the Arabic 
version of the questionnaires of this study that have been given to 30 Saudi Mathematics teachers outside the sample of this study. In order to assess the internal consistency of the questionnaires, Cronbach's alpha coefficients were calculated for each of questionnaire.The value of Cronbach's alpha coefficients for the questionnaire showed that the value is 0.943 . clearly showed that the value is accepted as suggested in Nunnally (1978).

The sampling technique in this study is a combination of cluster and stratified sampling. The cluster sampling technique is used to aim at Mathematics teachers in Tabuk educational region, Hail educational region and Sakaka educational region who works in the Saudi Arabia Government Secondary schools. There are 1297 teachers were registered as a Secondary school teacher in the Saudi Arabia as reported in Ministry of Education in Saudi Arabia for the year of 2015.The other consideration in sampling the participant is by stratifying the Mathematics teachers based on their gender and teaching experience. There are 200 teachers purposively selected from each region, which consists of 33 male teachers with less than 5 years of teaching experience, 34 male teachers with 6-15 years teaching experience, 33 male teachers with more than 16 years teaching experience, 33 female teachers with less than 5 years of teaching experience, 34 female teachers with 6-15 years teaching experience, and 33 female teachers with more than 16 years teaching experience. Thus, the total sample size of this study are 600 teachers. Unequal probability sampling is used to improve the efficiency of survey estimates. For example, in cluster sampling, one may greatly increase the efficiency by using sampling with probability proportional to cluster size as suggested inLu and Lemeshow (2018). Table 1 shows the distribution of samples for each region, for both male and female teachers with accordance by teaching experience a teacher has in years.

Table

Distribution of the Sample in Each Region

\begin{tabular}{|c|c|c|c|}
\hline \multirow{3}{*}{$\begin{array}{l}\text { NUMBER OF } \\
\text { YEARS }\end{array}$} & TEACHING & XPERIENCES & AMONG \\
\hline & \multicolumn{3}{|c|}{ MATHEMATICS TEACHERS } \\
\hline & $\begin{array}{l}\text { LESS THAN } 5 \\
\text { YEARS }\end{array}$ & $\begin{array}{lrl}6 & \text { TO } & 15 \\
\text { YEARS } & \end{array}$ & $\begin{array}{l}\text { MORE THAN } 16 \\
\text { YEARS }\end{array}$ \\
\hline MALE & 33 & 34 & 33 \\
\hline $\begin{array}{l}\text { TEACHERS } \\
\text { FEMALE } \\
\text { TEACHERS }\end{array}$ & 33 & 34 & 33 \\
\hline
\end{tabular}

\section{Data Analysis Techniques}

Instead of using raw data which is directly taken from the rating scale data of TPI questionnaire, this study used Logit data for the purpose the of comparing the TPI among Arab Mathematics teachers based on gender, teaching experiences and qualifications. This is due to the reason that the rating scale data of the revised version of TPI questionnaire is a Likert scale data. According to Wu and Adams (2007), Likert scale data is an ordinal data; therefore, the Rasch model formula could be utilized to transform the Likert scale data to interval data. When the Likert scale data is transformed into interval data, the data fulfils the fundamental requirement in conducting inferential statistics (Wu \& Adams, 2007).

Logit data is produced by the Rasch model which convert raw Likert scale data into item difficulty and person ability estimates on an approximately linear measurement scale. This linear measurement scale is an equal-interval scale measured in Logits (log odd units), reflecting the item difficulty and person's ability (Boone, Staver, \& Yale, 2014). Specifically, a Rasch-based rating scale model is chosen given the fact that all the items from TPI questionnaire use the same response format. In this sense, rating scale model which is one in which all items (or groups of items) share the same rating scale structure" (Linacre, 2000) is more reasonable than Partial Credit Model to be applied in this study. The equation of the rating scale model is presented below.

$$
\pi_{n i x}=\frac{e^{\sum_{j=0}^{x_{n i}}\left[\beta_{n}-\left(\delta_{i}+\tau_{j}\right)\right]}}{\sum_{k=0}^{m} e^{\sum_{j=0}^{x_{n i}}\left[\beta_{n}-\left(\delta_{i}+\tau_{j}\right)\right]}}
$$

According to formula above, $\pi$ nix represents the probability of person $n$ responding in category $x$ to item $i$, where $\beta n$ is person n's ability; diis the location or difficulty of item $i$ on the variable; $\tau$ jis the kththreshold location of the rating scale. These are constant across all items.

The comparison of Mathematics TPI based on gender is calculated using Person Logit values. The TPI raw scores of each participant in this study are converted into Person Logit values using Rasch formula. The participants' Logit values have been subgroup into two groups, namely: the logit values of the male teachers and the logit values of female teachers. The same procedures are also utilized for the comparison based on teaching experiences and qualifications.

\section{Results and Discussion}

An assumption of the equality of variances was checked using Levene's test. The purpose of using Levene's test for equality of variances is to examine whether the variance (variation) of scores for the two groups (male verses female) is the same. The result showed that the significance level for Levene's test is more than 0.05 . This means that the assumption of equal variances has not been violated; therefore, the t-value which are used for the interpretation is based on the first line of the table. The result of the independent-samples t-test showed that there was no significant difference in TPI scores in Logit unit for group of male Mathematics teachers $(\mathrm{M}=2.04, \mathrm{SD}=1.11)$ and group of female Mathematics teachers $(\mathrm{M}=2.02, \mathrm{SD}=$ $1.09 ; \mathrm{t}(374)=0.19, \mathrm{p}>0.05$, two-tailed) (Table 2 and Figure 1). 
Table

Mean of Person Logit Unit for Male and Female Teachers

\begin{tabular}{ccccc}
\hline & Gender & $\mathrm{N}$ & Mean & Std. Deviation \\
\hline Measure & Male & 187 & 2.04 & 1.11 \\
& Female & 189 & 2.02 & 1.09 \\
\hline
\end{tabular}

\begin{tabular}{|c|c|c|c|c|c|c|}
\hline & \multicolumn{2}{|c|}{ Equality of Variances } & \multicolumn{3}{|c|}{ t.test for Equality of Means } \\
\hline & & $\mathrm{F}$ & Sig. & $t$ & df & $\begin{array}{c}\text { Sig. } \\
\text { (2-tailed) }\end{array}$ \\
\hline Measure & $\begin{array}{c}\text { Equal variances } \\
\text { assumed }\end{array}$ & 0.01 & 0.91 & 0.19 & 374 & 0.85 \\
\hline & $\begin{array}{c}\text { Equal variances } \\
\text { not assumed }\end{array}$ & & & 0.19 & 373.71 & 0.85 \\
\hline
\end{tabular}

Figure 1. Result of Independent Samples T-Test

The findings showed that there is no significant difference of Mathematics TPI between male and female teacher. Regardless the segregation of male and female in Saudi Arabia, the differences of TPI between male and female teachers are not significant. The finding is contradicted with the previous study done which found that teachers in Saudi Arabia sometimes have some internal conflict about their identity as a teacher (Elyas, 2011). The sample of the study mentioned that there not all identity as a teacher should be fulfilled if the teacher's identity itself is not aligned with Arab Muslim identity (Elyas, 2011).

In relation with gender equality, according to Alsaleh (2012), for decades, Western media, scholars, and activists, have discussed the lack of equality that Saudi Arabian women face. They also think that Islam plays an important role in this kind of inequality between men and women (Alsaleh,2012). So, he argued that their discussions are apparently based on unreliable information gathered from people who perceive the proverbial glass as half-empty. Alsaleh (2012) in his study found that that women in Saudi Arabia, like women in any country, have their perception of equality. He also found that women in Saudi Arabia perceived that they have a pre-eminent role not only within their families but also outside their households. It can be argued that social gender theory can be used to explained the finding based on the view that gender differences as due to the differential treatment male and female s receive from the people in their lives and the pervasive gender stereotyped messages that people are exposed to in their environment. In relation with this notion, the Islam as a way of life explicitly maintains that as human beings, both sexes have the same origin and, therefore, are given equal rights (Jarallah, 1996) which implicate that male and female
Mathematics teachers did not perceive their TPI differently. A similar research was conducted to study the gender based in different context, as can be found in Fleishman, Spector, and Altman (2002) andSmith and Reise (1998).

Next, a one-way between-groups analysis of variance (ANOVA) was conducted to explore the impact of teaching experiences on TPI. Participants were divided into three groups according to their age (Group 1: 5 years and below; Group 2: 6 to 15 years; Group 3: 16 years and above) (Table 3 ). There was a statistically significant difference in TPI scores in Logit unit for the three teaching experiences groups: $\mathrm{F}(2,373)=40.83, \mathrm{p}=<0.05$ as showed in Table 4 . The effect size, calculated using eta squared, was .18. Posthoc comparisons using the Tukey HSD test indicated that the mean score for Group $1(\mathrm{M}=1.43, \mathrm{SD}=0.39)$ was significantly different from Group $2(\mathrm{M}=2.49, \mathrm{SD}=1.27)$ and Group $3(\mathrm{M}=2.28, \mathrm{SD}=1.18)$ as showed in Table 5. However, Group 2 did not differ significantly from either Group 3. Therefore, it can be interpreted that TPI scores of Group 2 and 3 are significantly higher compared to Group 1.

Table 3

Mean of Person Logit Unit for The Teachers Who Have (i) Less Than 5 Years of Teaching Experiences, (ii) 6 to 15 Years of Teaching Experience, and (iii) 16 Years of Teaching Experiences and More

\begin{tabular}{cccc}
\hline & & & Standard \\
& $\mathrm{N}$ & Mean & Deviation \\
\hline Less than 5 Years & 138 & 1.43 & 0.39 \\
6 to 15 Years & 114 & 2.49 & 1.27 \\
16 Years and Above & 124 & 2.28 & 1.18 \\
Total & 376 & 2.03 & 1.10 \\
\hline
\end{tabular}

Table

One Way Between-Groups Analysis of Variance

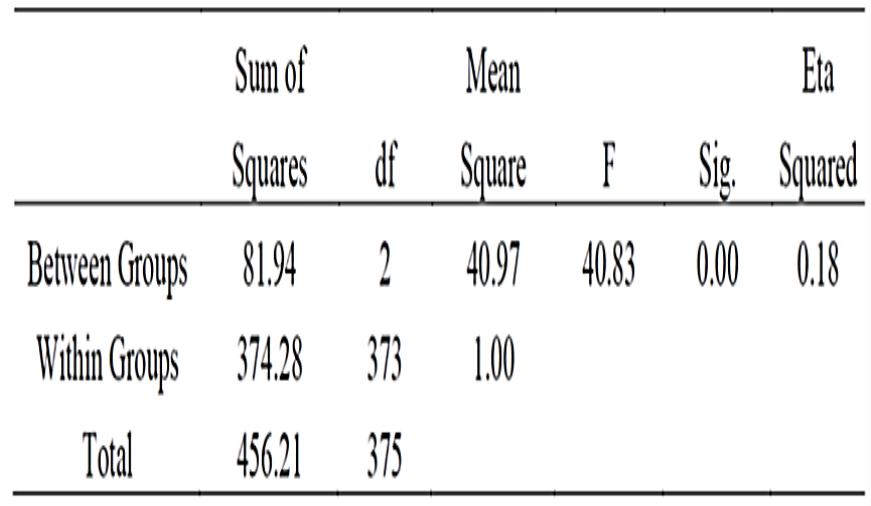

Table 5

Post Hoc Comparing using Tukey HSD Test 


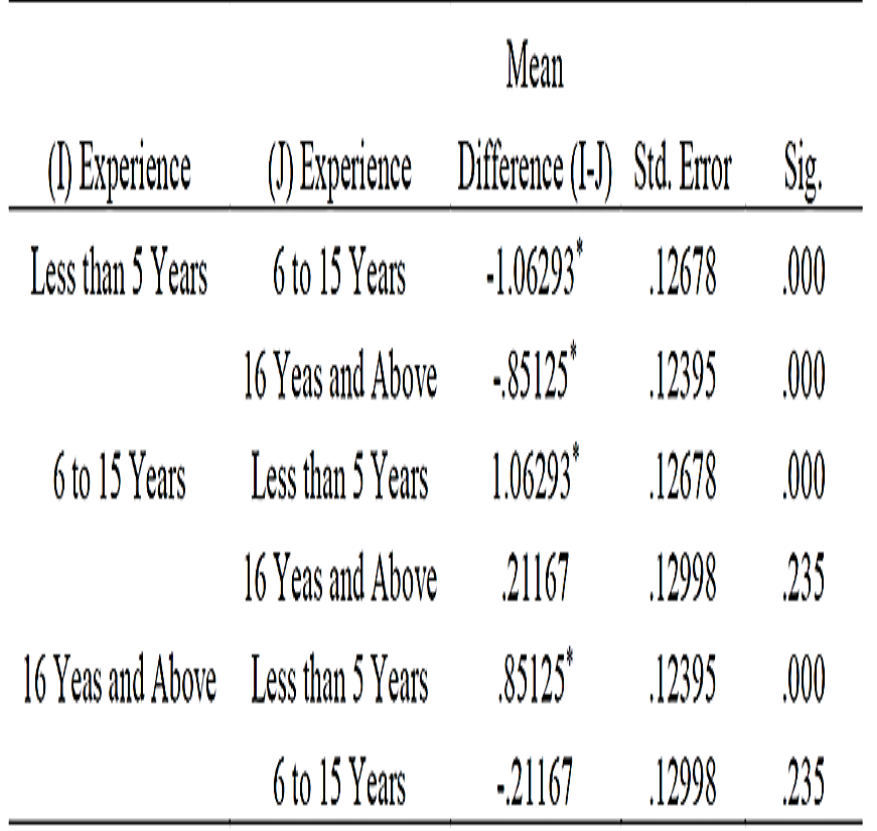

The findings showed that there is a significant difference of Mathematics TPI based on teaching experiences. The findings showed that when the more experiences the teachers are, the higher of their Mathematics TPI. Same findings will also found by Canrinus, Helms-Lorenz, Beijaard, Buitink, and Hofman (2011). They found that more experience lead to higher TPI. A similar outcome was obtained from previous research, such as, Li, Qin and Lei (2017) and Ramli, Talib, Hassan, and Manaf (2018). In addition to that, the findings showed that there is a significant difference of Mathematics TPI based on qualifications with the similar outcome obtain from previous research, such as Hope, Adamson, McManus, Chis, and Elder (2018) and Goliath-Yarde, and Roodt (2011).

The subsequent analysis is to compare TPI between Mathematics teacher with Bachelor degree qualification and Mathematics teacher which have higher degree qualification. The purpose of the Levene's test for equality of variances is examined whether the variance (variation) of scores for the two groups of qualification (Bachelor vs Higher Degree) is the same (Figure 2). The result showed that the significance level for Levene's test is less than 0.05 . This means that the assumption of equal variances has been violated; therefore, the t-value which are used for the purpose of the interpretation is based on the second line of the table. Therefore, the result of the independent-samples ttest showed that there was a significant difference in TPI scores in Logit unit for a group of Mathematics teachers with Bachelor qualification $(\mathrm{M}=1.56, \mathrm{SD}=0.42)$ and $\mathrm{a}$ group of Mathematics teachers with higher degree (Master or $\mathrm{PhD})$ qualifications $(\mathrm{M}=3.38, \mathrm{SD}=1.33$; $\mathrm{t}(102.79)=-$ 13.23, $\mathrm{p}<0.05$, two-tailed) (Figure 4.25). It can be concluded that TPI of Mathematics teachers with Master and $\mathrm{PhD}$ qualifications is significantly higher compared to Mathematics teachers with Bachelor degree (Table 6). These findings were also supported by Findlow (2012). The findings can be explained by looking at the concept of community of practice as a social theory of learning.

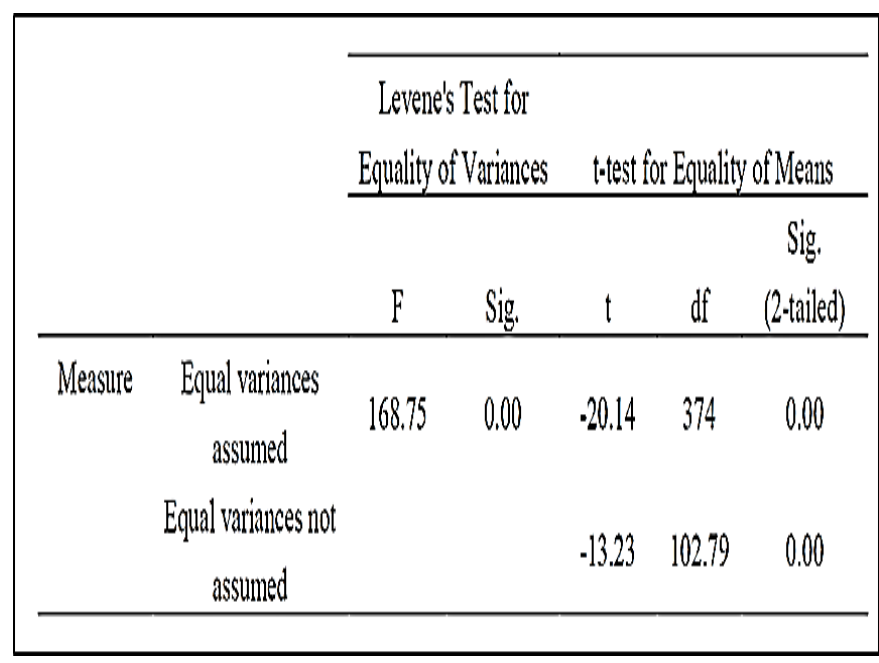

Figure 2. Result of Independence Samples T-Test

Table 6

Mean of Person Logit Unit for Participants Who Have Bachelor and Higher Degree (Master and PhD) Qualifications

\begin{tabular}{ccccc}
\hline & Oudification & $N$ & Meâl & Std. Deviation \\
\hline Measure & Bachelor & 279 & 1.56 & 0.42 \\
& Master and PhD & 97 & 3.38 & 1.33 \\
\hline
\end{tabular}

A social theory of learning by Lave and Wenger (1991) is used in this study to understand learning characterized it as a social process, which takes place within communities of practice. They argued that learning and identity construction are essentially social practices rather than individual cognitive or psychological functions, and that in practice, learning and identity are inseparable. Lave and Wenger explored the notion of learning as situated within particular contexts and they developed the concept of legitimate peripheral participation to describe the early stages of a learners' journey from being an apprentice on the periphery of the community of practice to becoming a full participant. Albaqi'i (2014) in his framework called this a schooling process which covers the practice of the more skilful or experiences teachers helping other teachers in what they need in the technical and administrative aspects of Mathematics. It is postulated in this study that experiences and degree of qualification plays a role in determining the progress level of the TPI construction among teachers in this study. Wenger (1998) went on to develop this concept further, suggesting that it is within these formal and informal communities of practice that learners negotiate meaning, and that this is fundamental to the construction of identities. 


\section{Conclusion and Implications}

In conclusion, it is found that that Math teachers with more teaching experiences have higher TPI compared to those who have less teaching experiences. It is also revealed that Math teachers with higher academic qualifications have higher TPI compared to those who have a lower academic qualification. The finding gives some theoretical implications of social learning theory and gender schema theory which serve as the basis for this study.

It is possible to consider the relationships between Mathematics teachers' identities and their participation in social practices (Skott, 2013) which naturally comprise both, teaching experiences in classrooms and teachers' learning in professional development courses. TPI is not as predetermined or given but rather as constructed within an active process of creation and recreation that is reflected in Britzman (2003) description of 'learning to teach' as 'the process of becoming: a time of formation and transformation, of scrutiny into what one is doing, and who one can become'. Skott (2019) emphasized that the TPI isdefined as a shifting experience of being a teacher, becoming a teacher, and sense of belonging as a teacher. Therefore, this study showed how teaching experiences and qualifications provide a framework for Mathematics teachers to construct their own ideas of 'how to be', 'how to act' and 'how to understand' their work and their place in the Kingdom of Saudi Arabia context. Wenger (1998) suggested that negotiability allows us to make meanings applicable to new circumstances, to enlist the collaboration of others, to make sense of events, or to assert our membership. Those members who are able to negotiate meanings that are personally significant are likely to become full members of the community, while those who are not able to contribute to the shared knowledge of the community are likely to be marginalized. This process from the perspective of social theory of learning is called peripheral legitimate participation. The newcomers to a community of practice learn from the more experienced members of the community and gradually move towards full participation, eventually becoming experienced members themselves.

The findings of the study showed that there is no significant difference on TPI between male and female Mathematics teachers. In relation with gender equality, according to Alsaleh (2012), for decades, Western media, scholars, and activists, have discussed the lack of equality that Saudi Arabian women face. They also think that Islam plays an important role in this kind of inequality between men and women as stated in Alsaleh (2012). So, he argued that their discussions are apparently based on unreliable information gathered from people who perceive the proverbial glass as half-empty. Alsaleh (2012) in his study found that that women in Saudi Arabia, like women in any country, have their perception of equality. He also found that women in Saudi Arabia perceived that they have a pre-eminent role not only within their families but also outside their households. Islam explicitly maintains that as human beings, both sexes have the same origin and, therefore, are given equal rights (Jarallah, 1996). Islam views women as playing an integral role in all aspects of society, including the workforce. According to the tradition of Prophet Mohammed, no ruling exists forbidding women to seek employment. According to Yonous (2011), if an Islamic government prohibits women from working, that government has violated Islamic Law. However, Yonous (2011) argued that gender inequality in Saudi Arabia has been discussed widely in recent years without taking into consideration the unique cultural history of a society like Saudi Arabia.

Cultural impact is one of the main factors affecting gender equality in any society. However,Al-Mohamed (2008) believed that Islam, as a religion, and the fact that the Saudi society is blessed with conservative rules and regulations is what is meant by the cultural impact that affects every aspect of Saudi life. Al-Mohamed (2008) states that although the Saudi government has improved educational opportunities for women, the next step is to boost the number of Saudi women in the workplace. She said "Currently, roughly 300,000 Saudi women work, comprising five percent of the Saudi national labour force. Ironically, the constraints on female employment mean that women in the workforce are generally much better qualified than men, with half of working women possessing a college degree, compared to only 16 percent of men" (Al-Mohamed, 2008). This circumstance also can be applied in teachers' working environment setting. In relation with this study, it can be speculated that gender also play a role in the construction of Mathematic TPI in Saudi Arabia context.

\section{References}

[1] Abdulghani, N., \& Abulnaeem, M. (2016). Professional identity and its relation with the professional satisfaction and self-esteem: Review paper. Journal of School of Education, Kafrelsheikh University, 2(1), 346-416.

[2] Abu-Raiya, H., \&Pargament, K. I. (2011). Empirically based psychology of Islam: Summary and critique of the literature. Mental Health, Religion \& Culture, 14(2), 93-115.

[3] Adler, J. B. (1998). Lights and limits: Recontextualising lave and wenger to theorise knowledge of teaching and of learning school Mathematics. In A. Watson (Ed.), Situated cognition and the learning of Mathematics (pp. 161-177). Oxford, England: Centre For Mathematics Education Research, University of Oxford Department of Educational Studies.

[4] Albaqi'i, N. (2014). Professional identity of a sample of unrwa teachers in jordan. Al-Manara Magazine, 20(2/b), 363-387.

[5] Ali, A. J., \& Azim, A. (1996). A cross-national perspective on managerial problems in a nonwestern country. The Journal of social psychology, 136(2), 165-172. 
[6] Ali, A. J., Taqi, A. A., \& Krishnan, K. (2010). Individualism, collectivism, and decision styles of managers in Kuwait. The Journal of Social Psychology, 137(5), 629-637.

[7] Al-Mohamed, A. (2008). Saudi women's rights: Stuck at a red light. Arab Insight, 2(1), 45-51.

[8] Alsaleh, S. A (2012). Gender Inequality in Saudi Arabia: Myth or Reality. Proceedings of International Conference on Innovation, Trade and Economics. 2-3 ${ }^{\text {rd }}$ June, Hong Kong.

[9] Alzubaidi, A. S., \& Al-Kahali, S. N. (2014). Gender, grade and anxiety differences in career identity statuses among ninth and tenth grades students in the sultanate of oman. American Arabic Academy of Science and Technology 5(13), 31-44. doi:10.12816/0015407.

[10] Ambusaidi, A., Alhashmi, A., \& AlRawahi, N. (2014). Omani TPI from their supervisors' perspectives: Comparison study between three school subjects. Turkish Journal of Teacher Education, 2(2), 96-108.

[11] Atiyyah, H. S. (1996). Expatriate acculturation in Arab Gulf countries. Journal of Management Development.

[12] Ball, D. L. (2003). What mathematical knowledge is needed for teaching Mathematics. Paper presented at the Secretary's Summit on Mathematics, US Department of Education, Washington, D.C.

[13] Ball, D. L., Lubienski, S. T., \& Mewborn, D. S. (2001). Research on teaching Mathematics: The unsolved problem of teachers' mathematical knowledge. In V. Richardson (Ed.), Handbook of research on teaching (4th ed., pp. 433-456). Washington, DC: AERA.

[14] Barry, H., Bacon, M. K., \& Child, I. L. (1957). A cross-cultural survey of some sex differences in socialization. Journalof Abnormal and Social Psychology, 55, 327-332.

[15] Beijaard, D., Meijer, P. C., \&Verloop, N. (2004). Reconsidering research on teachers' professional identity. Teaching and teacher education, 20(2), 107-128.

[16] Bem, S. L. (1981). Gender Scheme Theory: A Cognitive Account of Sex Typing. Psychological Review, 88(4),354-364.

[17] Bolívar, A., \& Domingo, J. (2006). The professional identity of secondary school teachers in spain: Crisis and reconstruction. Theory and Research in Education, 4(3), 339-355. doi:https://doi.org/10.1177/1477878506069105.

[18] Boone, W. J., Staver, J. R., \& Yale, M. S. (2014). Rasch Analysis in the Human Sciences. Dordrecht, Netherlands: Springer.

[19] Britzman, D. (2003). Practice makes practice. A critical study of learning to teach. New York: State University of New York Press.
[20] Bussey, K. (2011). Gender identity development. In Handbook of identity theory and research (pp. 603-628). Springer, New York, NY.Connell, R. W., \&Messerschmidt, J. W. (2005). Hegemonic masculinity: Rethinking the concept. Gender \& society, 19(6), 829-859.

[21] Canrinus, E. T., Helms-Lorenz, M., Beijaard, D., Buitink, J., \& Hofman, A. (2011). Profiling teachers' sense of professional identity. Educational Studies, 37(5), 593-608.

[22] Coldron, J., \& Smith, R. (1999). Active location in teachers' construction of their professional identities. Journal of Curriculum Studies, 31(6), 711-726.

[23] Creswell, J. (2003). Research design: Qualitative, quantitative, and mixed methods approaches $\left(2^{\text {nd }} e d.\right)$. Thousand Oaks, CA: Sage.

[24] Dörnyei, Z., \& Taguchi, T. (2009). Questionnaires in second language research: Construction, administration, and processing. Mahwah, NJ:: Routledge.

[25] El Sherif, H. (2012). Building the New Arab World. The G8 Camp David Summit: The Road to Recovery London: Newsdesk, 194196.

[26] Elyas, T (2011). Teacher Education and Identity in Saudi Arabia and Real Life Conflicts: A Case Study.In C. A. Coombe, L. Stephenson, \&Sufian Abu-Rmaileh (Eds.), Leadership and Management in English Language Teaching. Dubai, United Arab Emirates: TESOL Arabia.

[27] Ernest, P. (1998). Mathematical knowledge and context. In A. Watson (Ed.), Situated cognition and the learning of Mathematics (pp. 1-9). Oxford, England: Centre For Mathematics Education Research, University of Oxford Department of Educational Studies.

[28] Farnsworth, F., Kleanthous, I, \& Wenger, E. (2016). Communities of Practices as A Social Theory of Learning: A Conversation with Etienne Wenger. British Journal of Educational Studies, 64 (2), 1-22.

[29] Fleishman, J. A., Spector, W. D., \& Altman, B. M. (2002). Impact of differential item functioning on age and gender differences in functional disability. The Journals of Gerontology Series B: Psychological Sciences and Social Sciences, 57(5), S275-S284.

[30] Gliner, J. A., Morgan, G. A., \& Leech, N. L. (2011). Research methods in applied settings: An integrated approach to design and analysis. New York, NY: Routledge.

[31] Goldin, G. A., Hannula, M. S., HeydMetzuyanim, E., Jansen, A., Kaasila, R., Lutovac, S., . . . Pantziara, M. (2016). Attitudes, beliefs, motivation and identity in Mathematics education: An overview of the field and future directions. Hamburg: Springer Open. 
[32] Goliath-Yarde, L., \&Roodt, G. (2011). Differential item functioning of the UWES-17 in South Africa. SA Journal of Industrial Psychology, 37(1), 01-11.

[33] Graven, M. (2004). Investigating Mathematics teacher learning within an in-service community of practice: The centrality of confidence. Educational Studies in Mathematics, 57(2), 177-211.

[34] Graven, M., \& Lerman, S. (2014). Mathematics teacher identity. In S. Lerman (Ed.), Encyclopedia of Mathematics education (pp. 434438). London: Springer, Dordrecht.

[35] Grootenboer, P., Lowrie, T., \& Smith, T. (2006). Researching identity in Mathematics education: The lay of the land. In P. Grootenboer, R. Zevenbergen, \& M. Chinnappan (Eds.), Identities cultures and learning spaces. Proceedings of the 29th annual conference of the Mathematics Education Research Group of Australasia (Vol. 2, pp. 612-615). Canberra, ACT: MERGA.

[36] Hofstede, G. (2003). Cultural dimensions. www. geert-hofstede. com, consulta, 13.

[37] Hope, D., Adamson, K., McManus, I. C., Chis, L., \& Elder, A. (2018). Using differential item functioning to evaluate potential bias in a high-stake postgraduate knowledge-based assessment. BMC medical education, 18(1), 64.

[38] Hussein, H. B. (2017). Investigating the professional identity levels of elementary school Mathematics teachers. Journal of Huaman and Educational Sciences, Babylon University, 32, 84109.

[39] Jarallah, S. (1996). A Woman's Status in Islam. Manar Al-Sabeel Journal, 1(2), 45-53.

[40] Kelchtermans, G. (2009). Who i am in how $\mathrm{i}$ teach is the message: Self-understanding, vulnerability and reflection. Teachers and Teaching: Theory and Practice, 15(2), 257-272.

[41] King, J. E. (2015). Dysconscious racism: Ideology, identity, and the miseducation of teachers. In J. E. King (Ed.), Dysconscious racism, afrocentric praxis, and education for human freedom: Through the years i keep on toiling (pp. 125-139). New York: Routledge.

[42] Lave, J., \& Wenger, E. (1991). Situated learning: Legitimate peripheral participation. New York: Cambridge University Press.

[43] Li, H., Qin, Q., \& Lei, P. W. (2017). An examination of the instructional sensitivity of the TIMSS math items: A hierarchical differential item functioning Assessment, 22(1), 1-17.

[44] Linacre, J. M. (2000). Comparing "Partial Credit Models" (PCM) and "Rating Scale Models" (RSM). Rasch Measurement Transactions, 14(3),768.
[45] Loewen, S., \& Plonsky, L. (2015). An a-z of applied linguistics research methods. New York, NY: Palgrave Macmillan.

[46] Lu, B., \& Lemeshow, S. (2018). Score matching. In P. Irwing, T. Booth, \& D. J. Hughes (Eds.), The wiley handbook of psychometric testing: A multidisciplinary reference on survey, scale and test development (pp. 95-112). West Sussex: Wiley Blackwell.

[47] Martin, C. L., \& Halverson Jr, C. F. (1981). A schematic processing model of sex typing and stereotyping in children. Child development, 1119-1134.

[48] McBurney, D. H., \& White, T. L. (2009). Research methods. Belmont, CA: Cengage Learning.

[49] Mercer, N. (1995). The guided construction of knowledge: Talk amongst teachers and learners. Clevedon: Multilingual Matters.

[50] Nunnally, J. C. (1978). Psychometric theory ( $2^{\text {nd }}$ ed.). New York, NY: McGraw-Hill.

[51] Perry, D. G., \&Pauletti, R. E. (2011). Gender and adolescent development. Journal of Research on Adolescence, 21(1), 61-74.

[52] Philipp, R. A. (2007). Mathematics teachers' beliefs and affect. In F. K. L. Jr. (Ed.), Second handbook of research on Mathematics teaching (pp. 257-315). Charlotte, NC: Information Age Publishing.

[53] Ramli, N. F., Talib, O., Hassan, S. A., \&Manaf, U. K. A. (2018). Rasch Analysis and Differential Item Functioning of STEM Teachers' Instructional Preparedness Instrument for Urban and Rural Teachers. International Journal of Academic Research in Progressive Education and Development, 7(4), 211-222.

[54] Riazi, A. M. (2016). The routledge encyclopedia of research methods in applied linguistics. New York, NY: Routledge.

[55] Rø, K. (2015). Investigating Mathematics teacher identity development: A theoretical consideration. Paper presented at the CERME 9Ninth Congress of the European Society for Research in Mathematics Education, Czech Republic.

[56] Sabanciogullari, S., \& Dogan, S. J. I. J. o. N. P. (2015). Effects of the professional identity development programme on the professional identity, job satisfaction and burnout levels of nurses: A pilot study. International Journal of Nursing Practice, 21(6), 847-857.

[57] Sachs, J. (2005). Teacher education and the development of professional identity: Learning to be a teacher. In Connecting policy and practice: Challenges for teaching and learning in schools and universities (pp. 5-21). Routledge, Taylor and Francis Group. 
[58] Schwartz, S. H. (1994). Beyond individualism/collectivism: New cultural dimensions of values. Retrieved from https://psycnet.apa.org/record/1996-97151-003.

[59] Schalkwyk, J. (2000). Culture: a) Culture, Gender Equality and Development Cooperation. Canadian International Development Agency (June 2000). Retrieved October, 17, 2005.

[60] Skott, J. (2013). Understanding the role of the teacher in emerging classroom practices: searching for patterns of participation. ZDM Mathematics Education, 45(4), 547-559.

[61] Skott, J. (2019). Changing experiences of being, becoming, and belonging: TPI revisited. ZDM - Mathematics Education, 51(4),469-480.

[62] Smelser, N. J., \&Baltes, P. B. (Eds.). (2001). International encyclopedia of the social \&behavioral sciences (Vol. 11). Amsterdam: Elsevier.

[63] Smith, P. B., Fischer, R., Vignoles, V. L., \& Bond, M. H. (2013). Understanding social psychology across cultures: Engaging with others in a changing world. Sage.

[64] Smith, L. L., \&Reise, S. P. (1998). Gender differences on negative affectivity: An IRT study of differential item functioning on the Multidimensional Personality Questionnaire Stress Reaction scale. Journal of Personality and Social Psychology, 75(5), 1350.

[65] Tobin, D. D., Menon, M., Menon, M., Spatta, B. C., Hodges, E. V., \& Perry, D. G. (2010). The intrapsychics of gender: A model of self-socialization. Psychological Review, 117(2), 601.

[66] Wenger, E. (1998). Communities of practice: Learning, meaning, and identity. New York: Cambridge University Press.

[67] Wu, M. \& Adams, R. (2007). Applying the Rasch model to psycho-measurement: A practical approach. Melbourne: Educational Measurement Solutions.

[68] Yonous, F. (2011). Gender Equality in Islam. Saudi Arabia:Library of Congress.

[69] Živković, P. (2013). Professional development and teachers professional identity: Self-assessment in republic of serbia. Journal of Educational and Instructional Studies in the World, 3(1), 150-158. 